\title{
Impact of preoperative body mass index on perioperative outcomes is optimized by enhanced recovery protocols in laparoscopic radical cystectomy with intracorporeal urinary diversion
}

\author{
Houyi Wei ${ }^{1}$, Jiandong Gao ${ }^{2}$, Mingshuai Wang ${ }^{1}$, Wahafu Wasilijiang ${ }^{3}$, Pan Ai $^{2}$, Xiaoguang Zhou ${ }^{1}$, \\ Liyan Cui ${ }^{1}$, Liming Song ${ }^{1}$, Anshi $\mathrm{Wu}^{2}$, Nianzeng Xing ${ }^{3}$, Yinong Niu ${ }^{1}$ \\ ${ }^{1}$ Institute of Urology, Capital Medical University, Department of Urology, Beijing Chaoyang Hospital, Capital Medical University, Beijing, China; \\ ${ }^{2}$ Department of Anaesthesiology, Beijing Chaoyang Hospital, Capital Medical University, Beijing, China; Department of Urology, National Cancer \\ Center/National Clinical Research Center for Cancer/Cancer Hospital, Chinese Academy of Medical Sciences and Peking Union Medical College, \\ Beijing, China \\ Contributions: (I) Conception and design: All authors; (II) Administrative support: Nianzeng Xing, Yinong Niu; (III) Provision of study materials \\ or patients: Liming Song, Nianzeng Xing, Yinong Niu; (IV) Collection and assembly of data: All authors; (V) Data analysis and interpretation: All \\ authors; (VI) Manuscript writing: All authors; (VII) Final approval of manuscript: All authors. \\ Correspondence to: Yinong Niu, MD. 8 Gongren Tiyuchanag Nanlu, Chaoyang District, Beijing, China. Email: 18601020160@163.com.
}

Background: We aimed to examine whether body mass index (BMI) had an impact on clinical outcomes of laparoscopic radical cystectomy with intracorporeal urinary diversion. Furthermore, we analyzed the optimization of enhanced recovery protocols (ERPs) on the impact of BMI on clinical outcomes.

Methods: By searching our database, data of 83 consecutive patients were retrospectively collected, including 37 patients with a BMI $<24 \mathrm{~kg} / \mathrm{m}^{2}$ (group A) and 46 patients with a BMI $\geq 24 \mathrm{~kg} / \mathrm{m}^{2}$ (group B). The baseline and peri-operative variables of the two groups were compared. Subgroup analysis was conducted for ERPs (11 patients in group $\mathrm{A}_{1}, 18$ patients in group $\mathrm{B}_{1}$ ) and conventional recovery protocols (CRPs; 26 patients in group $A_{2}, 28$ patients in group $B_{2}$ ). The primary outcomes were 30-day overall complication rate and $\triangle \mathrm{ALB}_{\min }$ (reduction proportion of minimum albumin). The secondary outcomes were operative time and length of stay.

Results: The baseline variables were similar between the two groups $(\mathrm{P}>0.05)$. The 30 -day overall complication rate, operative time, and length of stay were similar between the two groups $(\mathrm{P}>0.05)$. But post-operative nausea and vomiting (PONV) was higher in group A than in group B (32.4\% vs. 8.7\%, $\mathrm{P}=0.014)$. Group A was associated with lower serum albumin level pre-operatively and on post-operative days $1-3 . \Delta \mathrm{ALB}_{\min }$ was higher in group A than in group $\mathrm{B}(33.08 \% \pm 9.88 \%$ vs. $27.92 \% \pm 8.52 \%, \mathrm{P}<0.05)$. In the subgroup analysis, the CRPs group presented similar results, with group $\mathrm{A}_{2}$ showing higher PONV rate, lower albumin level pre- and post-operatively, and higher level of reduction proportion $(\mathrm{P}<0.05)$. For the ERPs group, the PONV rate, pre-operative albumin level, and reduction proportion were similar between group $\mathrm{A}_{1}$ and $\mathrm{B}_{1}(\mathrm{P}>0.05)$. Multivariable analysis showed that $\mathrm{PONV}$ and CRPs were independently associated with $\triangle \mathrm{ALB}_{\min } \geq 34 \%(\mathrm{P}<0.05)$.

Conclusions: BMI had no impact on the 30-day overall complication rate, operative time, and length of stay of patients who underwent laparoscopic radical cystectomy with intracorporeal urinary diversion. BMI $<24 \mathrm{~kg} / \mathrm{m}^{2}$ was associated with higher PONV rate and more albumin loss, both of which could be optimized by ERPs.

Keywords: Enhanced recovery protocols (ERPs); body mass index (BMI); intracorporeal urinary diversion (ICUD); post-operative nausea and vomiting (PONV); serum albumin 
Submitted Feb 27, 2021. Accepted for publication Apr 06, 2021.

doi: $10.21037 /$ tau-21-171

View this article at: http://dx.doi.org/10.21037/tau-21-171

\section{Introduction}

Radical cystectomy (RC) with lymph node dissection is regarded as the gold standard for treatment of muscleinvasive bladder cancer. Several randomized controlled trials indicated that minimally invasive surgery, including laparoscopic and robot-assisted radical cystectomy (LRC/ RARC), could benefit patients during the peri-operative period with equivalent oncologic results as compared with the open approach (1-5). However, these trials only included extracorporeal urinary diversion and evidence of intracorporeal urinary diversion (ICUD) is sparse.

Enhanced recovery protocols (ERPs) originated from colorectal surgery (6) and have been gradually implemented in other surgeries such as RC (7). High-level evidence for its performance in RC is limited. Only a few studies have reported the outcomes of ERPs implementation on ICUD (8-10).

The impact of body mass index (BMI) on the clinical outcomes of ICUD, including parameters such as operative time, length of stay and complications, has been sporadically reported before $(11,12)$. However, to the best of our knowledge, whether BMI could influence peri-operative albumin level and whether ERPs would optimize the clinical impact of BMI on clinical outcomes have not been examined before. In this study, we retrospectively compared the peri-operative outcomes of patients with $\mathrm{BMI}<24$ or $\geq 24 \mathrm{~kg} / \mathrm{m}^{2}$ and conducted a subgroup analysis for ERPs and conventional recovery protocols (CRPs).

We present the following article in accordance with the STROBE reporting checklist (available at http://dx.doi. org/10.21037/tau-21-171).

\section{Methods}

\section{Study population}

A total of 83 patients with bladder cancer underwent LRC with ICUD between March 2014 and September 2020 at our institution. The 83 patients were divided into two groups according to the Chinese BMI criteria. Group A included 37 patients with BMI $<24 \mathrm{~kg} / \mathrm{m}^{2}$ and group B included 46 patients with $B M I \geq 24 \mathrm{~kg} / \mathrm{m}^{2}$. Subgroup analysis was conducted for ERPs (11 patients in group $\mathrm{A}_{1}$,
18 patients in group $B_{1}$ ) and CRPs (26 patients in group $A_{2}$, 28 patients in group $B_{2}$ ). The ERPs of our institution have been performed since April 2017. The detailed elements of ERPs and CRPs are presented in Table 1. The study was conducted in accordance with the Declaration of Helsinki (as revised in 2013). The study was approved by the Institutional Review Board of Beijing Chaoyang Hospital, Capital Medical University (NO.: 2020-Ke-546) and informed consent for this retrospective analysis was waived.

\section{Surgical technique}

Our institution has performed nearly 500 cases of RC since 2000. LRC was performed using a six-port transperitoneal approach. Our technique has also been previously reported $(13,14)$. Standard lymph node dissection was performed conventionally; extended lymph node dissection was performed when needed. An intracorporeal ileal conduit or Studer orthotopic ileal neobladder was performed in accordance with the surgeon's opinions and the patient's preference was also taken into consideration. Modifications to both types of urinary diversions, including procedure adjustment and a novel end-to-end reflux uretero-intestinal anastomosis, have been previously described $(13,14)$. After the ileal conduit, the retroperitoneum was closed so that the conduit and uretero-intestinal anastomosis were totally retroperitonealized. The neobladder was constructed with bilateral isoperistaltic afferent limbs. A single three-lumen catheter and bilateral single-J stents were placed through the urethra without performing a suprapubic cystostomy.

\section{Data collection}

Baseline characteristics and perioperative outcomes were retrospectively collected. The serum albumin concentration was measured pre-operatively and on post-operative days (POD) 1-3. Moreover, within three PODs, the minimum albumin $\left(\mathrm{ALB}_{\min }\right)$ level was also analyzed. The reduction degree was defined as the difference between the pre- and post-operative albumin level. The reduction proportion ( $\triangle \mathrm{POD} 1-3$ and $\triangle \mathrm{ALB}_{\min }$ ) was defined as the reduction degree/pre-operative albumin level $\times 100 \%$. Complications within 30 days were collected and graded according to 
Table 1 Elements of ERPs and CRPs

\begin{tabular}{|c|c|c|}
\hline Time point & ERPs & CRPs \\
\hline \multirow{2}{*}{ Preoperative } & 2. Evaluation of comorbidities and medical optimization & $\begin{array}{l}\text { 2. Evaluation of comorbidities and medical } \\
\text { optimization }\end{array}$ \\
\hline & $\begin{array}{l}\text { 3. Evaluation of nutritional status, and oral support if } \\
\text { needed }\end{array}$ & 3. None \\
\hline \multicolumn{3}{|l|}{ Prior to surgery } \\
\hline \multirow[t]{2}{*}{$3 d$} & Normal diet & Low residue diet \\
\hline & & Oral antibiotics (fluoroquinolones and metronidazole) \\
\hline \multirow[t]{4}{*}{$1 d$} & Low residue diet & Potable water \\
\hline & Laxatives & Enema \\
\hline & & Oral antibiotics \\
\hline & & Parenteral nutrition \\
\hline $6 \mathrm{~h}$ & Potable water & NPO \\
\hline \multirow[t]{2}{*}{$2 \mathrm{~h}$} & NPO & NPO \\
\hline & Oral carbohydrate loading $2 \mathrm{~h}$ prior to surgery ( $5 \mathrm{~mL} / \mathrm{kg}$ ) & \\
\hline $30 \mathrm{~min}$ & $\begin{array}{l}\text { Intravenous antibiotics; Another dose of intravenous } \\
\text { antibiotics if operative time exceeds } 3 \mathrm{~h}\end{array}$ & Intravenous antibiotics \\
\hline \multirow{7}{*}{ Intraoperative } & 3. Avoidance of long-acting sedatives and opioids & 3. Conventional anesthetics \\
\hline & 4. Prevention of hypothermia (warm air blower or blanket) & 4. None \\
\hline & 5. Goal-directed fluid administration & 5. None \\
\hline & 6. Local infiltration of ropivacaine before wound closure & 6. None \\
\hline & 7. Intravenous antemetics before awaking & 7. Intravenous antemetics before awaking \\
\hline & 8. Pelvic drainage tube placement & 8. Pelvic drainage tube placement \\
\hline & 9. Patient controlled intravenous analgesia placement & $\begin{array}{l}\text { 9. Patient controlled intravenous analgesia } \\
\text { placement }\end{array}$ \\
\hline \multirow[t]{2}{*}{ Postoperative } & 1. Recumbent position & 1. Recumbent position without pillow \\
\hline & $\begin{array}{l}\text { 2. Opioid-sparing analgesia; NSAIDs for those with VAS } \\
\text { more than } 4\end{array}$ & 2. Conventional analgesics \\
\hline
\end{tabular}

Table 1 (continued) 
Table 1 (continued)

\begin{tabular}{lll}
\hline Time point & \multicolumn{1}{c}{ ERPs } & \multicolumn{1}{c}{ CRPs } \\
\hline & $\begin{array}{l}\text { 3. Moderate mobilization } 4 \mathrm{~h} \text { after surgery } \\
\text { 4. Potable water } 6 \mathrm{~h} \text { after surgery, } 50 \mathrm{~mL} / \mathrm{h} \text {; Adding to } \\
100 \mathrm{~mL} / \mathrm{h} \text { on postoperative day } 1 \text { if tolerated; resuming } \\
\text { liquid diet after passing flatus and converting to normal } \\
\text { diet gradually }\end{array}$ & 4. NPO until passing flatus \\
$\begin{array}{l}\text { 5. Chewing gum } 3 \text { times a day until passing flatus, } \\
\text { 30 min each time }\end{array}$ & 5. None \\
$\begin{array}{l}\text { 6. Avoidance of fluid over-infusion, } \leq 30 \mathrm{~mL} / \mathrm{kg} \\
\text { 7. Thromboprophylaxis: low molecular weight heparin } \\
\text { and compression stockings }\end{array}$ & $\begin{array}{l}\text { 6. None } \\
\text { 7. Thromboprophylaxis: low molecular weight }\end{array}$ \\
\hline
\end{tabular}

ERPs, enhanced recovery protocols; CRPs, conventional recovery protocols; LRC, laparoscopic radical cystectomy; ICUD, intracorporeal urinary diversion; NPO, nil per os; NGT, nasogastric tube; NSAIDs, non-steroidal anti-inflammatory drugs; VAS, visual analogue scale.

the Clavien-Dindo classification. Post-operative fever was defined as a body temperature of $\geq 38^{\circ} \mathrm{C}$. Post-operative nausea and vomiting (PONV) was defined as the need for rescue anti-emetics.

\section{Statistical analysis}

Statistical analyses were performed using the SPSS v26. Normally distributed continuous variables were presented as mean values with standard deviations and analyzed using the Student's $t$-test. Non-normally distributed continuous variables were presented as median and interquartile ranges and analyzed using the Mann-Whitney $\mathrm{U}$ test. Categorical variables were compared using Pearson's Chi-square test or Fisher's exact test. Univariable and multivariable regression analysis were performed for $\triangle \mathrm{ALB}_{\min } \geq 34 \%$. Statistical significance was set at $\mathrm{P}<0.05$.

\section{Results}

All patients underwent LRC with ICUD with no transition to open surgery. The baseline characteristics were similar between group A and B (Table 2). Eleven patients in group A and 18 in group B adhered to the ERPs (29.7\% vs. $39.1 \%, \mathrm{P}=0.488$ ). Peri-operative outcomes and albumin loss are presented in Table 3. Most peri-operative parameters were similar in the two groups, including operative time, estimated blood loss, length of stay, and 30-day overall complications $(\mathrm{P}>0.05)$. However, the post-operative PONV rate was significantly higher in group A $(32.4 \%$ vs. $8.7 \%$, $\mathrm{P}=0.014)$. When comparing peri-operative albumin level, group A demonstrated lower albumin level pre-operatively $(39.49 \pm 4.85$ vs. $42.29 \pm 3.95 \mathrm{~g} / \mathrm{L}, \mathrm{P}=0.005)$ and on POD $1-3$ and $\mathrm{ALB}_{\min }(26.23 \pm 3.92$ vs. $30.30 \pm 3.08 \mathrm{~g} / \mathrm{L}, \mathrm{P}<0.001)$. The reduction proportion was higher in group $\mathrm{A}$ on $\triangle \mathrm{POD} 1-2$ and $\triangle \mathrm{ALB}_{\min }(33.08 \% \pm 9.88 \%$ vs. $27.92 \% \pm 8.52 \%, \mathrm{P}=0.013)$.

Subgroup analysis for ERPs and CRPs with BMI $<24$ or $\geq 24 \mathrm{~kg} / \mathrm{m}^{2}$ are presented in Table 4 . In the CRPs subgroup, $\mathrm{BMI}<24 \mathrm{~kg} / \mathrm{m}^{2}$ also showed a higher PONV rate $(42.3 \%$ vs. $7.1 \%, \mathrm{P}=0.007)$, lower albumin level pre-operatively $(38.98 \pm 4.62$ vs. $41.85 \pm 3.88 \mathrm{~g} / \mathrm{L}, \mathrm{P}=0.016)$ and on POD $1-3$ and $\mathrm{ALB}_{\text {min }}(24.77 \pm 3.45$ vs. $29.33 \pm 2.93 \mathrm{~g} / \mathrm{L}, \mathrm{P}<0.001)$, and higher reduction proportion on $\triangle \mathrm{POD} 1-2$ and $\triangle \mathrm{ALB}_{\min }$ $(35.93 \% \pm 9.42 \%$ vs. $29.57 \% \pm 7.65 \%, \mathrm{P}=0.009)$. In ERPs subgroup, the clinical outcomes were optimized as patients with BMI $<24$ or $\geq 24 \mathrm{~kg} / \mathrm{m}^{2}$ showed similar PONV rate (9.1\% vs. $11.1 \%, \mathrm{P}=1.000)$, similar pre-operative albumin level $(40.69 \pm 5.41$ vs. $42.96 \pm 4.09 \mathrm{~g} / \mathrm{L}, \mathrm{P}=0.210)$, and similar reduction proportion on $\triangle \mathrm{POD} 1-2$ and $\triangle \mathrm{ALB}_{\min }$ (26.35\% $\pm 7.64 \%$ vs. $25.35 \% \pm 9.38 \%, \mathrm{P}=0.769)$.

Multivariable analysis in Table 5 showed that PONV [odds ratio (OR) 3.901, 95\% confidence interval (CI): $1.067-14.256, \mathrm{P}=0.040]$ and $\mathrm{CRPs}(\mathrm{OR} 3.243,95 \% \mathrm{CI}$ : $1.014-10.367, \mathrm{P}=0.047)$ were independently associated with $\triangle \mathrm{ALB}_{\min } \geq 34 \%$.

\section{Discussion}

Our study is based on the following problems: (I) the impact of BMI on clinical outcomes and on the perioperative albumin level in LRC with ICUD is unclear; (II) hypoalbuminemia is common after various surgeries, 
Table 2 Baseline characteristics of patients with group A $\left(<24 \mathrm{~kg} / \mathrm{m}^{2}\right)$ and B $\left(\geq 24 \mathrm{~kg} / \mathrm{m}^{2}\right)$

\begin{tabular}{|c|c|c|c|}
\hline Characteristics & Group A (N=37) & Group B (N=46) & $\mathrm{P}$ \\
\hline No. gender, n (\%) & & & 1.000 \\
\hline Male & $31(83.8)$ & $39(84.8)$ & \\
\hline Female & $6(16.2)$ & $7(15.2)$ & \\
\hline$|-| \mid$ & $34(91.9)$ & $37(80.4)$ & \\
\hline III & $3(8.1)$ & $9(19.6)$ & \\
\hline Median age-adjusted Charlson comorbidity index & 3 [2-5] & $4[2-5]$ & 0.611 \\
\hline No. transurethral resection of bladder tumor, $\mathrm{n}(\%)$ & $19(51.4)$ & $21(45.7)$ & 0.662 \\
\hline No. history of smoking, $\mathrm{n}(\%)$ & $18(48.6)$ & $19(41.3)$ & 0.515 \\
\hline No. type of urinary diversion, $\mathrm{n}(\%)$ & & & 1.000 \\
\hline Ileal conduit & $23(62.2)$ & $28(60.9)$ & \\
\hline Orthotopic ileal neobladder & $14(37.8)$ & $18(39.1)$ & \\
\hline No. with enhanced recovery protocols, $\mathrm{n}(\%)$ & $11(29.7)$ & $18(39.1)$ & 0.488 \\
\hline
\end{tabular}

including RC, and has a predictive value for mortality and morbidity. Intravenous albumin supplementation is mainly used for remedial treatment, although the safety and efficacy of this treatment is controversial; and (III) the experience of implementing ERPs in LRC with ICUD has rarely been reported, and whether ERPs will change the impact of BMI remains unclear. We aimed to determine the impact of BMI on clinical outcomes and perioperative albumin level in LRC with ICUD, and whether ERPs could optimize the impact of BMI.

ICUD has been initiated since 2000 (15). Owing to its technical difficulty, the implementation of ICUD is still limited. No randomized controlled trials have been conducted to compare clinical outcomes between intracorporeal and extracorporeal urinary diversion. Research from the International Robotic Cystectomy Consortium indicated that the proportion of ICUD has increased significantly in high-volume centers in North America and Europe over the years. Compared with extracorporeal urinary diversion, ICUD reduced operative time and estimated blood loss but was associated with more complications and readmissions. The complications decreased with increasing surgeon volume, which indicated the learning curve of this technique (16).

The association between BMI and the clinical outcomes in RC has been previously reported. Ahmadi et al. (12) reported the results for RARC with ICUD. They divided the patients into four groups according to BMI $(<25,25-$ $29.9,30-34.9, \geq 35 \mathrm{~kg} / \mathrm{m}^{2}$ ), and found that peri-operative, pathologic, and early oncologic results were all similar among the four groups; therefore, RARC with ICUD could be performed safely and feasibly in obese patients. Bagrodia et al. (17) reported that a high BMI would not increase peri-operative complications and costs in RC. However, several other studies have shown that high BMI has an adverse impact on clinical outcomes, such as higher major complication rate (18), more post-operative ileus (19), higher disease recurrence rate and cancer-specific mortality (20). Ghodoussipour et al. (21) also reported that patients with a high BMI were more likely to experience intra-operative conversion (from planned orthotopic to non-orthotopic urinary diversion).

In our study of LRC with ICUD, most peri-operative parameters, including 30-day overall complication rate, operative time, estimated blood loss and length of stay, were similar between group A and B. An interesting finding 
Table 3 Perioperative results of patients with group A $\left(<24 \mathrm{~kg} / \mathrm{m}^{2}\right)$ and B $\left(\geq 24 \mathrm{~kg} / \mathrm{m}^{2}\right)$

\begin{tabular}{|c|c|c|c|}
\hline Variables & Group A (N=37) & Group B (N=46) & $\mathrm{P}$ \\
\hline Median estimated blood loss (mL) & $200[100-300]$ & $200[100-275]$ & 0.756 \\
\hline No. intraoperative blood transfusion, $\mathrm{n}(\%)$ & $2(5.4)$ & $4(8.7)$ & 0.882 \\
\hline Median time to liquid diet (day) & 73 [14-108] & 72 [12-96] & 0.102 \\
\hline Median length of stay (day) & $11[8-15]$ & $11[9-15]$ & 0.927 \\
\hline No. readmission, $\mathrm{n}(\%)$ & $1(2.7)$ & $4(8.7)$ & 0.499 \\
\hline No. 30-d overall complication, $\mathrm{n}(\%)$ & $28(75.7)$ & $33(71.7)$ & 0.804 \\
\hline No. 30-d minor complication, $\mathrm{n}(\%)$ & $27(73.0)$ & $32(69.6)$ & 0.810 \\
\hline Constipation & $14(37.8)$ & $13(28.3)$ & 0.480 \\
\hline No. 30-d major complication, n (\%) & $1(2.7)$ & $2(4.3)$ & 1.000 \\
\hline Preoperative ALB (g/L) & $39.49 \pm 4.85$ & $42.29 \pm 3.95$ & 0.005 \\
\hline \multicolumn{4}{|l|}{ Postoperative ALB (g/L) } \\
\hline POD1 & $27.22 \pm 3.61$ & $31.41 \pm 3.13$ & $<0.001$ \\
\hline POD2 & $27.17 \pm 3.61$ & $31.24 \pm 3.01$ & $<0.001$ \\
\hline POD3 & $27.51 \pm 3.73$ & $31.49 \pm 3.06$ & $<0.001$ \\
\hline $\mathrm{ALB}_{\min }$ & $26.23 \pm 3.92$ & $30.30 \pm 3.08$ & $<0.001$ \\
\hline \multicolumn{4}{|l|}{ Reduction proportion, n (\%) } \\
\hline$\triangle \mathrm{POD} 1$ & $31.22 \pm 9.07$ & $25.33 \pm 8.25$ & 0.003 \\
\hline$\triangle \mathrm{POD} 2$ & $30.54 \pm 9.32$ & $25.72 \pm 8.25$ & 0.019 \\
\hline$\triangle \mathrm{POD3}$ & $29.08 \pm 10.60$ & $26.01 \pm 7.70$ & 0.188 \\
\hline$\Delta \mathrm{ALB}_{\min }$ & $33.08 \pm 9.88$ & $27.92 \pm 8.52$ & 0.013 \\
\hline
\end{tabular}

Reduction degree = preoperative albumin level - postoperative albumin level; reduction proportion = reduction degree/preoperative albumin level $\times 100 \%$. PONV, postoperative nausea and vomiting; ALB, albumin; POD, postoperative day; ALB $_{\text {min }}$, minimum albumin within 3 postoperative days.

was that patients in group A had more PONV, which has rarely been reported in RC in previous studies. Increased $\mathrm{BMI}$ was thought to be associated with a higher PONV rate. However, this opinion has been doubted over the past several years, and many studies have found opposite results (22-25). In a recent large-scale study, Kim et al. (25) performed propensity score matching for 103,561 patients who underwent general anesthesia. The results showed that 
Table 4 30-day complication and perioperative albumin level in ERPs and CRPs group with group $\mathrm{A}_{1}\left(<24 \mathrm{~kg} / \mathrm{m}^{2}\right) v s . \mathrm{B}_{1}\left(\geq 24 \mathrm{~kg} / \mathrm{m}^{2}\right)$, and group $\mathrm{A}_{2}\left(<24 \mathrm{~kg} / \mathrm{m}^{2}\right) v s . \mathrm{B}_{2}\left(\geq 24 \mathrm{~kg} / \mathrm{m}^{2}\right)$

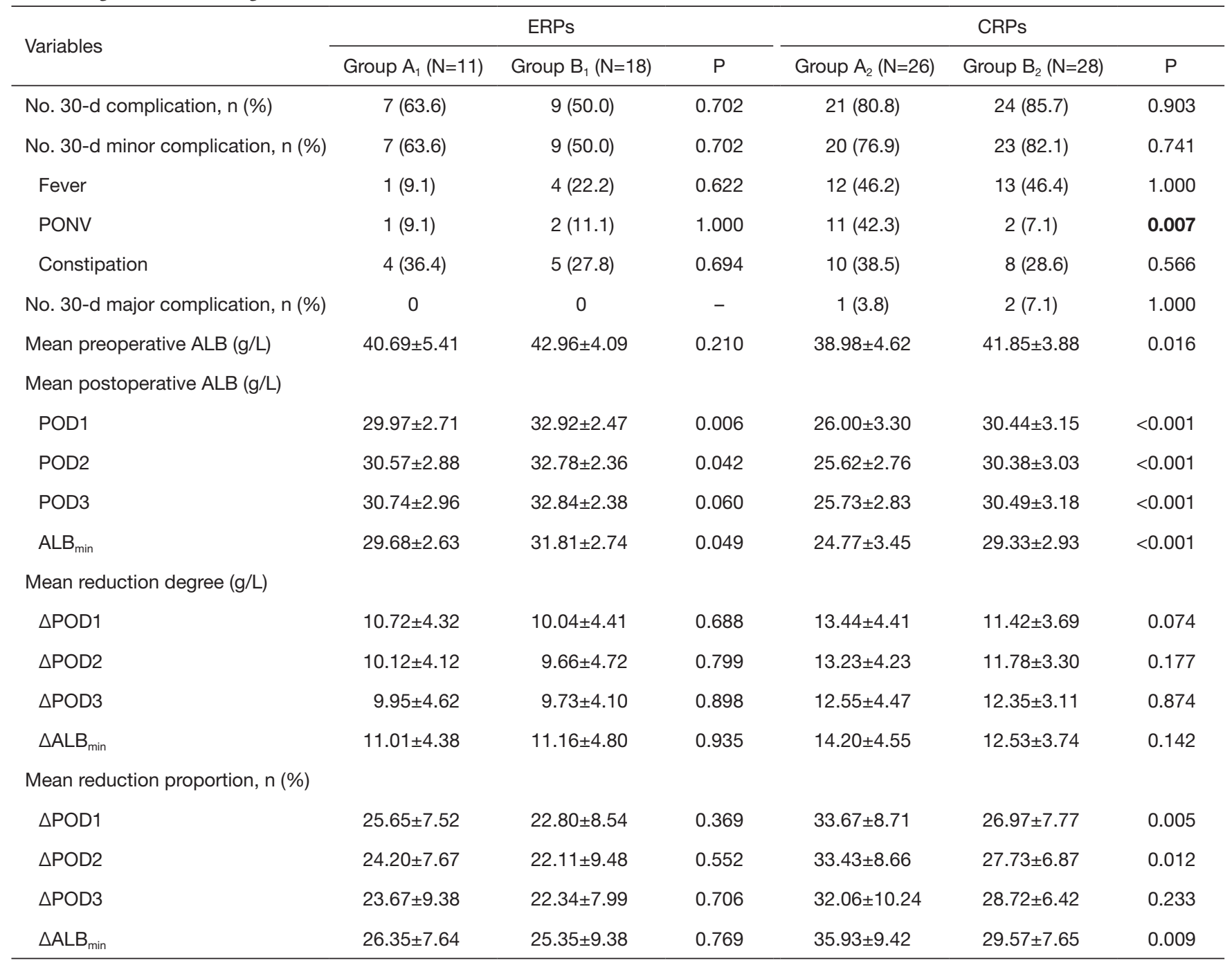

Reduction degree = preoperative albumin level - postoperative albumin level; reduction proportion = reduction degree/preoperative albumin level $\times 100 \%$. ERPs, enhanced recovery protocols; CRPs, conventional recovery protocols; PONV, postoperative nausea and vomiting; $A L B$, albumin; POD, postoperative day; $A_{L B} B_{\min }$, minimum albumin within 3 postoperative days.

both overweight $\left(25.1-30 \mathrm{~kg} / \mathrm{m}^{2}\right)$ and obese $\left(>30 \mathrm{~kg} / \mathrm{m}^{2}\right)$ patients experienced less PONV than normal patients $\left(18.5-25 \mathrm{~kg} / \mathrm{m}^{2}\right)$. Another study (26) found that during 24-72 h after total hip/knee arthroplasty, patients with a lower BMI would experience more PONV. The mechanism underlying this phenomenon has not yet been clarified. Receptors of dopamine, acetylcholine, histamine, and serotonin participate in inducing nausea and vomiting (27). A study (28) compared 10 obese with 10 normal patients and indicated that the availability of dopamine $D_{2}$ receptor was significantly lower in obese patients; BMI had a negative impact on $\mathrm{D}_{2}$ receptors. Other studies $(29,30)$ indicated that leptin, which could facilitate histamine release, decreased more significantly in obese-than-normal patients undergoing fasting. Therefore, during perioperative fasting, a higher reduction of leptin in obese patients may also contribute to this phenomenon.

Another finding was that group A presented lower albumin level pre- and post-operatively and a higher reduction proportion. Univariable analysis showed that a BMI of $<24 \mathrm{~kg} / \mathrm{m}^{2}$ had an impact on $\triangle \mathrm{ALB}_{\min } \geq 34 \%$. This finding has not been reported before; therefore, it would be 
Table 5 Univariable and multivariable regression analysis of factors associated with $\triangle \mathrm{ALB}_{\min } \geq 34 \%$

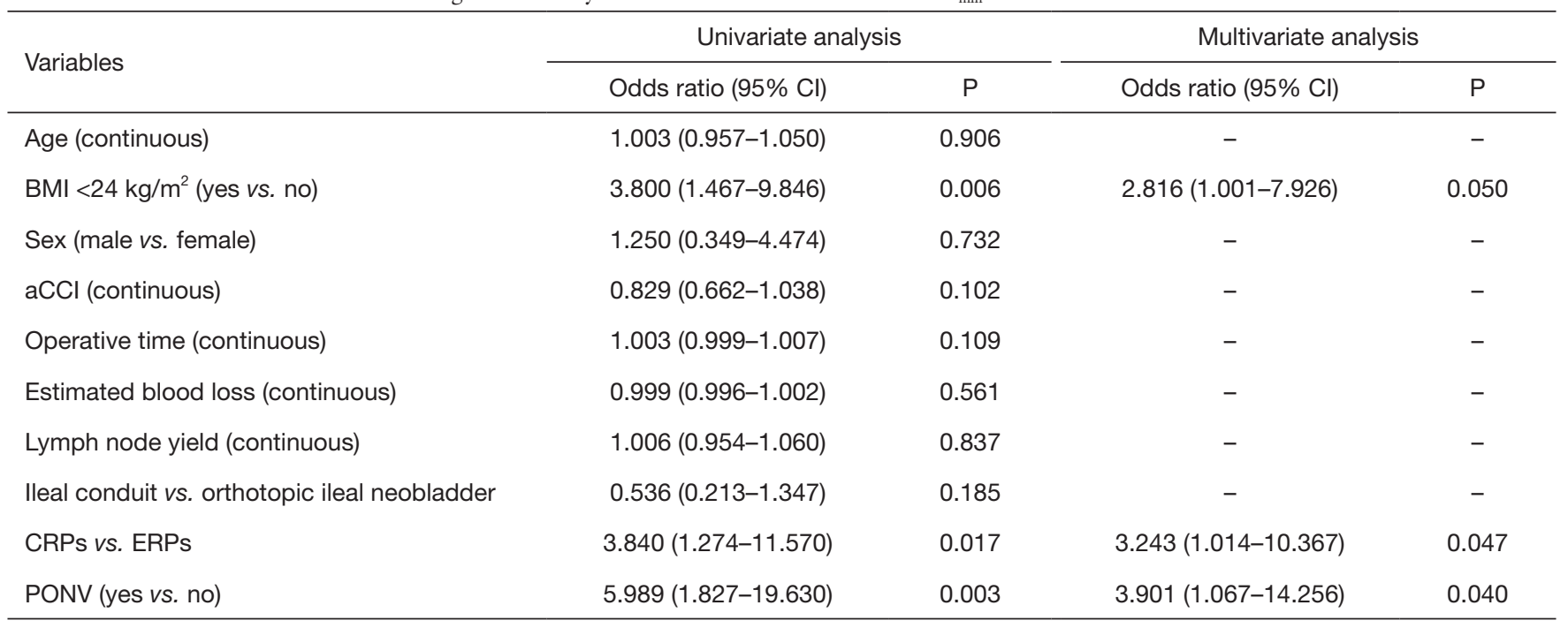

$\mathrm{Cl}$, confidence intervals; $\mathrm{BMI}$, body mass index; aCCl, age-adjusted Charlson Comorbidity Index; ERPs, enhanced recovery protocols; CRPs, conventional recovery protocols; PONV, postoperative nausea and vomiting.

difficult to determine the underlying rationale. We think that the possible reasons included: (I) patients with higher BMI demonstrated better nutritional status, thus elevating baseline serum albumin level; (II) due to different baseline albumin level, even if the reduction degree was similar in both groups, group B demonstrated higher post-operative albumin level and lower reduction proportion; (III) in this cohort, patients with a higher BMI presented lower rates of PONV, which could reduce nutrient loss and avoid prolonged bowel function recovery. Multivariable analysis also indicated that PONV was independently associated with $\triangle \mathrm{ALB}_{\min } \geq 34 \%$ (Table 5); and (IV) it was reported that after intra-operative infusion of $20 \%$ albumin, BMI was positively correlated with intravascular half-life of the infused albumin, which indicated a possibility that higher $\mathrm{BMI}$ was associated with longer intravascular persistence of albumin (31).

ERPs are considered an evidence-based multi-modal and multi-disciplinary pathway for peri-operative management. It aims to minimize the stress response and optimize the recovery process. ERPs have been introduced in RC in recent years and have shown definite advantages. However, evidence of the implementation of ERPs on ICUD is limited. Koupparis et al. (8) reported the results of a combination of intracorporeal RARC (iRARC) and ERPs, which was compared with open $\mathrm{RC}$ with or without ERPs. The length of stay was reduced from 13 to 8 days $(\mathrm{P}<0.001)$. The total complication rate was reduced from $48 \%$ to $31 \%$, although the difference was not significant. Tan et al. (10) compared the results of open RC and iRARC with or without ERPs. iRARC with ERPs demonstrated a shorter length of stay when compared with iRARC or open surgery alone (7 vs. 11 vs. 17 days, $\mathrm{P}<0.001)$. It also presented fewer 90 -day overall complications and readmissions $(\mathrm{P}<0.05)$.

In our study, comparative results between BMI $<24$ or $\geq 24 \mathrm{~kg} / \mathrm{m}^{2}$ in the CRPs group were similar to those in the whole cohort. PONV occurrence was $42.3 \%$ in group $\mathrm{A}_{2}$ and $7.1 \%$ in group $B_{2}(P=0.007)$. Group $A_{2}$ also showed lower level of serum albumin pre- and post-operatively and a higher level of reduction proportion $(\mathrm{P}<0.05)$. However, the results in the ERPs group were different. PONV was $9.1 \%$ in group $A_{1}$ and $11.1 \%$ in group $B_{1}(P=1.000)$. A multi-institutional, randomized controlled trial (32) from China showed that ERPs demonstrated shorter recovery to bowel movement ( $88 v$ vs. $100 \mathrm{~h}$ ), fluid (68 vs. $96 \mathrm{~h}$ ) or regular diet (125 vs. $168 \mathrm{~h}$ ), and ambulation (64vs. $72 \mathrm{~h}$ ) when compared with conventional treatment. Tan et al. (10) also reported that iRARC combined with ERPs could decrease gastrointestinal complications. Based on these reports and our results, ERPs showed potential advantages in optimizing bowel function recovery and reducing PONV occurrence.

Although the albumin level on POD 1-2 was still lower in group $\mathrm{A}_{1}$, the pre-operative level and its reduction proportion showed no difference between groups $A_{1}$ and $\mathrm{B}_{1}$. Multivariable analysis showed that CRPs were 
independently associated with $\triangle \mathrm{ALB}_{\min } \geq 34 \%$. These results indicated that the impact of $\mathrm{BMI}$ on peri-operative albumin level was optimized by ERPs implementation. It has been reported that transcapillary escape, which occurs during the inflammatory response, accounts for $77 \%$ of peri-operative albumin loss $(33,34)$. Thus, ERPs could optimize perioperative albumin level, which might be attributed to its aim of minimizing surgical stress and related inflammatory response.

Our study had several limitations: (I) the first of which was its small sample size. When performing subgroup analysis, there would be fewer cases divided into four subgroups; (II) due to the small sample size, we divided the whole cohort into two groups according to BMI ( $<24$ or $\geq 24 \mathrm{~kg} / \mathrm{m}^{2}$ ), not strictly following the Chinese BMI criteria, which spans from underweight to obese class III; (III) although there were several novel findings in this research, most of them had not been previously reported, such as the association between BMI and peri-operative albumin level, and that ERPs could optimize the impact of BMI on clinical outcomes. The underlying mechanisms are unclear, and we could only explain our results using limited evidence; (IV) multivariable analysis showed a strong correlation between PONV and $\triangle A L B_{\min } \geq 34 \%$. However, both of them occurred in the early post-operative period; it was difficult to clarify which one caused the other.

\section{Conclusions}

In our research on LRC with ICUD, BMI had no impact on the 30-day overall complication rate, operative time, and length of stay. BMI $<24 \mathrm{~kg} / \mathrm{m}^{2}$ was associated with higher PONV rate and more albumin loss, both of which could be optimized by ERPs.

\section{Acknowledgments}

We would like to thank Editage (www.editage.cn) for English language editing.

Funding: None.

\section{Footnote}

Reporting Checklist: The authors have completed the STROBE reporting checklist. Available at http://dx.doi. org/10.21037/tau-21-171

Data Sharing Statement: Available at http://dx.doi. org/10.21037/tau-21-171

Peer Review File: Available at http://dx.doi.org/10.21037/ tau-21-171

Conflicts of Interest: All authors have completed the ICMJE uniform disclosure form (available at http://dx.doi. org/10.21037/tau-21-171). NX serves as an unpaid editorial board member of Translational Andrology and Urology from Mar 2020 to Feb 2022. The other authors have no conflicts of interest to declare.

Ethical Statement: The authors are accountable for all aspects of the work in ensuring that questions related to the accuracy or integrity of any part of the work are appropriately investigated and resolved. The study was conducted in accordance with the Declaration of Helsinki (as revised in 2013). The study was approved by the Institutional Review Board of Beijing Chaoyang Hospital, Capital Medical University (NO.: 2020-Ke-546) and informed consent for this retrospective analysis was waived.

Open Access Statement: This is an Open Access article distributed in accordance with the Creative Commons Attribution-NonCommercial-NoDerivs 4.0 International License (CC BY-NC-ND 4.0), which permits the noncommercial replication and distribution of the article with the strict proviso that no changes or edits are made and the original work is properly cited (including links to both the formal publication through the relevant DOI and the license). See: https://creativecommons.org/licenses/by-nc-nd/4.0/.

\section{References}

1. Lin T, Fan X, Zhang C, et al. A prospective randomised controlled trial of laparoscopic vs open radical cystectomy for bladder cancer: perioperative and oncologic outcomes with 5-year follow-up. Br J Cancer 2014;110:842-9.

2. Bochner BH, Dalbagni G, Sjoberg DD, et al. Comparing Open Radical Cystectomy and Robot-assisted

Laparoscopic Radical Cystectomy: A Randomized Clinical Trial. Eur Urol 2015;67:1042-50.

3. Khan MS, Gan C, Ahmed K, et al. A Single-centre early phase randomised controlled three-arm trial of open, robotic, and laparoscopic radical cystectomy (CORAL). Eur Urol 2016;69:613-21.

4. Bochner BH, Dalbagni G, Marzouk KH, et al. Randomized trial comparing open radical cystectomy and 
robot-assisted laparoscopic radical cystectomy: oncologic outcomes. Eur Urol 2018;74:465-71.

5. Khan MS, Omar K, Ahmed K, et al. Long-term Oncological Outcomes from an Early Phase Randomised Controlled Three-arm Trial of Open, Robotic, and Laparoscopic Radical Cystectomy (CORAL). Eur Urol 2020;77:110-8.

6. Kehlet H. Multimodal approach to control postoperative pathophysiology and rehabilitation. Br J Anaesth 1997;78:606-17.

7. Collins JW, Patel H, Adding C, et al. Enhanced Recovery After Robot-assisted Radical Cystectomy: EAU Robotic Urology Section Scientific Working Group Consensus View. Eur Urol 2016;70:649-60.

8. Koupparis A, Villeda-Sandoval C, Weale N, et al. Robotassisted radical cystectomy with intracorporeal urinary diversion: impact on an established enhanced recovery protocol. BJU Int 2015;116:924-31.

9. Collins JW, Adding C, Hosseini A, et al. Introducing an enhanced recovery programme to an established totally intracorporeal robot-assisted radical cystectomy service. Scand J Urol 2016;50:39-46.

10. Tan WS, Tan MY, Lamb BW, et al. Intracorporeal robotassisted radical cystectomy, together with an enhanced recovery programme, improves postoperative outcomes by aggregating marginal gains. BJU Int 2018;121:632-9.

11. Poch MA, Stegemann A, Chandrasekhar R, et al. Does body mass index impact the performance of robot-assisted intracorporeal ileal conduit? J Endourol 2012;26:857-60.

12. Ahmadi N, Clifford TG, Miranda G, et al. Impact of body mass index on robot-assisted radical cystectomy with intracorporeal urinary diversion. BJU Int 2017;120:689-94.

13. Niu YN, Wei HY, Sun J, et al. Modified ileal conduit intracorporeally accomplished following laparoscopic radical cystectomy. 39th Congress of the Société Internationale d'Urologie, Athens, October 17-20, 2019:80-1.

14. Xing NZ, Kang N, Song LM, et al. Laparoscopic radical cystectomy with novel orthotopic neobladder with bilateral isoperistaltic afferent limbs: initial experience. Int Braz J Urol 2017;43:57-66.

15. Gill IS, Fergany A, Klein EA, et al. Laparoscopic radical cystoprostatectomy with ileal conduit performed completely intracorporeally: the initial 2 cases. Urology 2000;56:26-9.

16. Hussein AA, Elsayed AS, Aldhaam NA, et al. A comparative propensity score-matched analysis of perioperative outcomes of intracorporeal vs extracorporeal urinary diversion after robot-assisted radical cystectomy: results from the International Robotic Cystectomy Consortium. BJU Int 2020;126:265-72.

17. Bagrodia A, Grover S, Srivastava A, et al. Impact of body mass index on clinical and cost outcomes after radical cystectomy. BJU Int 2009;104:326-30.

18. Izol V, Deger M, Baltaci S, et al. The Effect of Body Mass Index on Oncological and Surgical Outcomes in Patients Undergoing Radical Cystectomy for Bladder Cancer: A Multicenter Study of the Association of Urooncology, Turkey. Int J Clin Pract 2021;75:e13750.

19. Svatek RS, Fisher MB, Williams MB, et al. Age and body mass index are independent risk factors for the development of postoperative paralytic ileus after radical cystectomy. Urology 2010;76:1419-24.

20. Dabi Y, Rouscoff Y, Anract J, et al. Impact of body mass index on the oncological outcomes of patients treated with radical cystectomy for muscle-invasive bladder cancer. World J Urol 2017;35:229-35.

21. Ghodoussipour S, Ahmadi N, Hartman N, et al. Factors influencing intraoperative conversion from planned orthotopic to non-orthotopic urinary diversion during radical cystectomy. World J Urol 2019;37:1851-5.

22. Nitahara K, Sugi $Y$, Shono S, et al. Risk factors for nausea and vomiting following vitrectomy in adults. Eur J Anaesthesiol 2007;24:166-70.

23. Ukai T, Ebihara G, Watanabe M. Opioid administration via epidural catheter is a risk factor for postoperative nausea and vomiting in total hip arthroplasty: A retrospective study. J Orthop Sci 2018;23:973-6.

24. Silva AC, O'Ryan F, Poor DB. Postoperative nausea and vomiting (PONV) after orthognathic surgery: a retrospective study and literature review. J Oral Maxillofac Surg 2006;64:1385-97.

25. Kim JH, Hong M, Kim YJ, et al. Effect of Body Mass Index on Postoperative Nausea and Vomiting: Propensity Analysis. J Clin Med 2020;9:1612.

26. Wang Y, Yang Q, Lin J, et al. Risk factors of postoperative nausea and vomiting after total hip arthroplasty or total knee arthroplasty: a retrospective study. Ann Transl Med 2020;8:1088.

27. Gan TJ. Postoperative Nausea and Vomiting_Can It Be Eliminated? JAMA 2002;287:1233-6.

28. Wang GJ, Volkow ND, Logan J, et al. Brain dopamine and obesity. Lancet 2001;357:354-7.

29. Boden G, Chen X, Mozzoli M, et al. Effect of fasting on serum leptin in normal human subjects. J Clin Endocrinol Metab 1996;81:3419-23. 
30. Jørgensen EA, Knigge U, Warberg J, et al. Histamine and the regulation of body weight. Neuroendocrinology 2007;86:210-4.

31. Hasselgren E, Zdolsek M, Zdolsek JH, et al. Long Intravascular Persistence of 20\% Albumin in Postoperative Patients. Anesth Analg 2019;129:1232-9.

32. Lin T, Li K, Liu H, et al. Enhanced recovery after surgery for radical cystectomy with ileal urinary diversion: a multi-institutional, randomized, controlled trial from

Cite this article as: Wei $\mathrm{H}$, Gao J, Wang M, Wasilijiang W, Ai P, Zhou X, Cui L, Song L, Wu A, Xing N, Niu Y. Impact of preoperative body mass index on perioperative outcomes is optimized by enhanced recovery protocols in laparoscopic radical cystectomy with intracorporeal urinary diversion. Transl Androl Urol 2021;10(5):2008-2018. doi: 10.21037/tau-21-171 the Chinese bladder cancer consortium. World J Urol 2018;36:41-50.

33. Fleck A, Raines G, Hawker F, et al. Increased vascular permeability: A major cause of hypoalbuminaemia in disease and injury. Lancet 1985;1:781-4.

34. Smeets HJ, Kievit J, Dulfer FT, et al. Analysis of postoperative hypalbuminaemia: A clinical study. Int Surg 1994;79:152-7. 